Gut, 1965, 6, 338

\title{
Action of 5-hydroxytryptamine on the human stomach, duodenum, and jejunum in vitro
}

\author{
D. J. FISHLOCK, A. G. PARKS, AND J. VERONICA DEWELL \\ From the London Hospital, London
}

EDITORIAL SYNOPSIS These pharmacological studies on human alimentary smooth muscle show that different regions of gut respond differently. Where a response is obtained it is due to a direct action on the muscle.

It is generally accepted that alimentary smooth muscle contracts in the presence of 5-hydroxytryptamine (5-HT). This appears to be true for several animal species. Erspamer $(1940,1952)$ showed that rat duodenum and mouse jejunum were sensitive to small concentrations of this amine. Later Gaddum (1953) and Gaddum and Hameed (1954) reported that rat duodenum and colon, rabbit duodenum and jejunum, and guinea-pig duodenum, jejunum, and ileum all contracted in the presence of 5-HT and Gaddum described specific receptors for this amine. The fundus of the rat stomach was found to be a useful preparation for the assay of 5-HT, the longitudinal muscle being more sensitive than the circular (Vane, 1957).

It is also well known that the human alimentary tract is sensitive to 5-HT, but most investigators have confined their attention to the effects of this amine on the motility and intraluminal pressure of the jejunum and ileum. Hendrix, Atkinson, Clifton, and Ingelfinger (1957) showed that intravenously administered 5-HT abruptly increased the intraluminal pressure of the human jejunum. This effect was inhibited by atropine but unaltered by hexamethonium, and it was suggested that 5-HT acted on the cholinergic nerves distal to the ganglionic synapse. Haverback and Davidson (1958) also demonstrated that 5-HT increased jejunal activity in the normal human subject. This action was inhibited by the oral administration of 2-bromolysergic acid diethylamide but not by atropine. Daniel, Honour, and Bogoch (1960) reported that intravenously administered 5-HT produced an initial spasm of the human ileum which was followed by rhythmic contractions lasting several minutes. Antagonism was not achieved with atropine, morphine, nalorphine, or promethazine. However, 2-bromolysergic acid did antagonise the effect.
They concluded that intravenously administered 5-HT acted directly on the muscle of the ileum.

Recently, the human ileum and colon have been investigated using a standard pharmacological technique in vitro (Fishlock and Parks, 1963a; Fishlock, 1964). The terminal ileum was found to contract in the presence of a small concentration of 5-HT. The ascending colon was comparatively insensitive and variable in response, but the whole of the distal half of the colon was very sensitive and regularly relaxed. This remarkable difference between the ileum and the colon prompted us to investigate other regions of the human intestinal tract, and this paper reports the results obtained from the longitudinal and circular muscle of the stomach, duodenum, and jejunum.

\section{METHOD}

Longitudinal and circular muscle strips, about $20 \mathrm{~mm}$. long by $2 \mathrm{~mm}$. wide, were taken from the stomach, duodenum, or jejunum from patients undergoing partial gastrectomy, antrectomy, and pyloroplasty, or resection of the jejunum. Muscle strips were taken only from regions that appeared healthy and had not been obstructed. Most of the patients suffered from benign or malignant gastric ulceration.

Some of the strips consisted of full-thickness bowel wall, but the majority had the mucosa and submucosa removed. The strips were collected in the operating theatre and immediately placed in a modified Krebs's solution at room temperature and quickly taken to the laboratory. There they were set up in an isolated organ bath in modified Krebs's solution gassed with $95 \% \mathrm{O}_{2}$ and $5 \% \mathrm{CO}_{2}$ at $37^{\circ} \mathrm{C}$. and placed under a tension of $2 \mathrm{~g}$. The preparation was left for about 30 minutes, by which time spontaneous activity had developed in the gastric and jejunal strips. Recording was made on a smoked drum with a direct-writing isotonic lever and a vibrator was used to overcome friction (Bülbring, Crema, and Saxby, 1958). 
The solution used contained (mM) Na 140, K 5.9, $\mathrm{Ca} 2 \cdot 5, \mathrm{Mg} \mathrm{1} \cdot 2, \mathrm{Cl} 122, \mathrm{HCO}_{3} 25, \mathrm{H}_{2} \mathrm{PO}_{4} 1 \cdot 2, \mathrm{SO}_{4} 1 \cdot 2$, and dextrose $11 \cdot 5$.

Acetylcholine chloride, 5-hydroxytryptamine creatinine sulphate, atropine sulphate, procaine hydrochloride, and lysergic acid diethylamide tartrate were used. Concentrations refer to the salts.

All the patients received the usual pre-operative medication of atropine $0.6 \mathrm{mg}$. or scopolamine $0.5 \mathrm{mg}$. with omnopon $20 \mathrm{mg}$. or morphine $16 \mathrm{mg}$. The anaesthesia was induced with thiopentone and maintained with muscle relaxants, nitrous oxide, and sometimes with the addition of halothane.

\section{RESULTS}

It should be noted that each muscle strip contained the myenteric plexus situated between the muscle layers, but that only the strips with mucosa contained the submucous plexus in addition. The removal of the mucosa from the muscle strips made no difference in the type of response obtained or in the sensitivity of the preparations to acetylcholine or 5-HT.

\section{STOMACH}

Forty-one strips from 17 patients were investigated. Specimens were taken from both the body and the antrum. Regular spontaneous contraction and relaxation developed in most experiments, the frequency of which was much slower than that typical of smooth muscle from the jejunum.

BODY OF STOMACH (27 STRIPS) All of these preparations contracted in the presence of acetylcholine $(0.1 \mu \mathrm{g} . / \mathrm{ml}$. and above). This response was antagonized by atropine ( $50 \mu \mathrm{g} . / \mathrm{ml}$. for $5 \mathrm{~min}$.) and not by procaine $(50 \mu \mathrm{g} . / \mathrm{ml}$. for $30 \mathrm{~min}$.) or lysergic acid diethylamide (L.S.D.) $(0 \cdot 1 \mu \mathrm{g} . / \mathrm{ml}$. for $5 \mathrm{~min}$.).

Longitudinal muscle (16 strips) In all experiments 5-HT caused the longitudinal muscle to contract (Fig. 1). The sensitivity, i.e., the minimum concentration producing a response, varied from $5 \mathrm{ng} . / \mathrm{ml}$. to $100 \mathrm{ng} . / \mathrm{ml}$. In four of the strips the response was only slight and did not increase with higher concentrations of the drug. The response to 5-HT was antagonized by L.S.D. $(0 \cdot 1 \mu \mathrm{g} . / \mathrm{ml}$. for $5 \mathrm{~min}$.) but was not affected by procaine $(50 \mu \mathrm{g}$. $/ \mathrm{ml}$. for $30 \mathrm{~min}$.) or atropine $(50 \mu \mathrm{g} . / \mathrm{ml}$. for $5 \mathrm{~min}$.).

The contraction produced by 5-HT tended to be prolonged and rarely did the muscle relax to its original length. Under these circumstances it was found necessary to stretch gently the preparation as suggested by Vane (1957), who found a similar difficulty in using strips from the rat stomach. This procedure did not alter the responsiveness of the preparation.
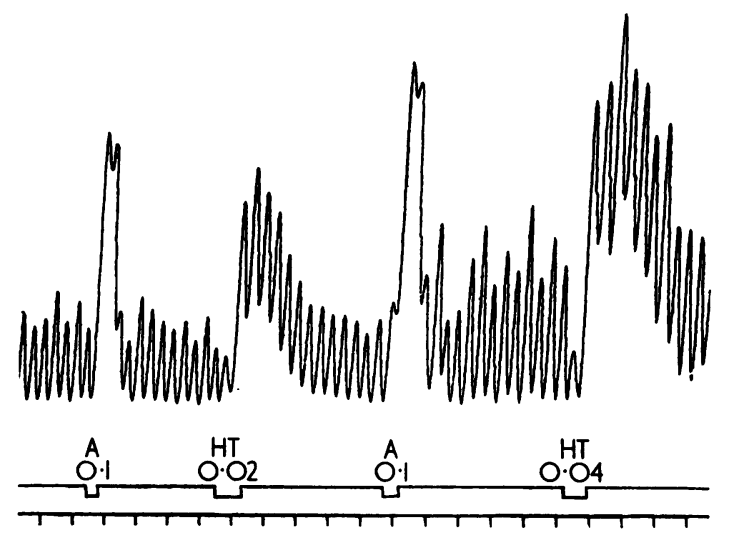

FIG. 1. Body of stomach: longitudinal muscle. $A=$ acetylcholine. $H T=5$-hydroxytryptamine. Concentration of drugs expressed as $\mu \mathrm{g} . / \mathrm{ml}$. Strip length $27 \mathrm{~mm}$. Tension $2 \mathrm{~g}$. Lever magnification $\times 7$. Time interval 60 seconds.

Circular muscle (11 strips) Seven strips did not respond to $5-\mathrm{HT}$ in the dose range $5 \mathrm{ng} . / \mathrm{ml}$.$100 \mu \mathrm{g} . / \mathrm{ml}$. Three strips showed a very slight response $(20 \mathrm{ng} . / \mathrm{ml}$.), which did not increase with higher concentrations. The insensitivity of the circular muscle was very striking when compared with the responses obtained from the longitudinal muscle. However, one strip did show a response to 5-HT similar to the longitudinal muscle.

ANTRUM (14 STRIPS) All strips contracted in the presence of acetylcholine $(0 \cdot 1 \mu \mathrm{g} . / \mathrm{ml}$. and above). 5-Hydroxytryptamine (10 ng./ml.-100 $\mu \mathrm{g}$./ml.) failed to evoke any response from either the longitudinal (eight strips) (Fig. 2) or the circular muscle (six strips). Several of these experiments were carried out simultaneously with strips taken from the body of the same stomach.

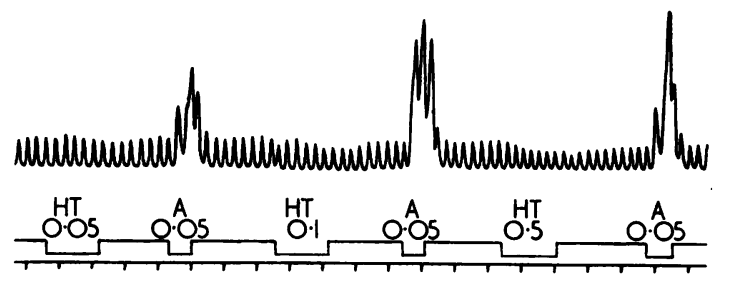

FIG. 2. Pyloric antrum: longitudinal muscle. $H T=5$ hydroxytryptamine. $A=$ acetylcholine. Concentration of drugs expressed as $\mu \mathrm{g} . / \mathrm{ml}$. Strip length $25 \mathrm{~mm}$. Tension $2 \mathrm{~g}$. Lever magnification $\times 7$. Time interval 60 seconds. 

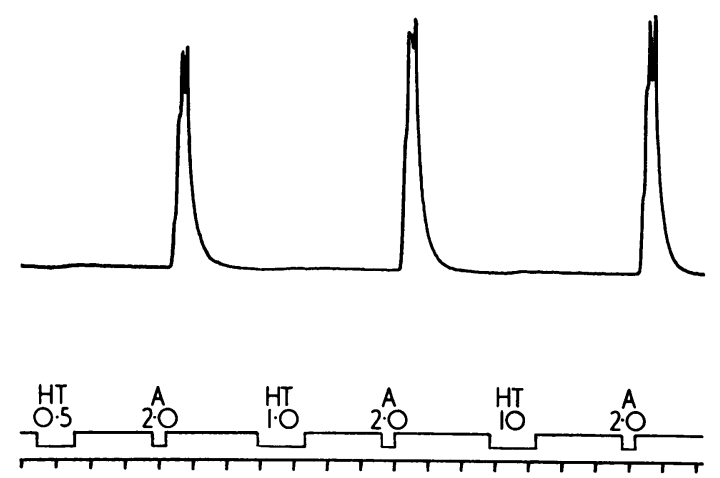

FIG. 3. First part of duodenum: circular muscle. $H T=5$ hydroxytryptamine. $A=$ acetylcholine. Concentration of drugs expressed as $\mu \mathrm{g} . / \mathrm{ml}$. Strip length $18 \mathrm{~mm}$. Tension $2 \mathrm{~g}$. Lever magnification $\times 7$. Time interval 60 seconds.

\section{DUODENUM}

It has been found difficult to obtain specimens from this region. From the first part of the duodenum 12 strips were taken from nine patients.

FIRST PART Eight circular and four longitudinal muscle strips were investigated. Regular spontaneous activity did not occur in any experiment and tone was either absent or slight. One longitudinal strip developed single maximal contractions at intervals of approximately 15 minutes. Despite this lack of spontaneous activity all strips responded to acetylcholine $(0 \cdot 1 \mu \mathrm{g} . / \mathrm{ml}$.$) . The duodenal preparations$ were all insensitive to 5-HT (Fig. 3). Ten of them did not respond at all (10 $\mathrm{ng} . / \mathrm{ml} .-50 \mu \mathrm{g}$. $/ \mathrm{ml}$.). Two of the longitudinal strips gave a very slight contraction $(5-10 \mu \mathrm{g} . / \mathrm{ml}$.) but this response did not increase with higher concentrations.

SECOND PART Only one longitudinal strip was obtained from this region. It was extremely sensitive and contracted to both acetylcholine $(0.5 \mathrm{ng} . / \mathrm{ml}$.) and 5-HT $(0.5 \mathrm{ng} . / \mathrm{ml}$.). This was in such contrast to the comparatively insensitive first part that it has been included in this paper.

\section{JEJUNUM}

Fourteen strips from 10 patients were investigated, seven being circular and seven longitudinal. These specimens were taken from the proximal part of the jejunum, i.e., within the first metre.

Both circular and longitudinal muscle exhibited rapid spontaneous activity and developed tone. All strips were very sensitive to acetylcholine and contracted in the presence of 10 to $100 \mathrm{ng} . / \mathrm{ml}$. This response was blocked by atropine, but was unaffected by L.S.D. and procaine. 5-Hydroxytryptamine (1-100 $\mathrm{ng} . / \mathrm{ml}$.) caused both longitudinal and circular muscle to contract. This response was antagonized by L.S.D. (Fig. 4), but was not affected

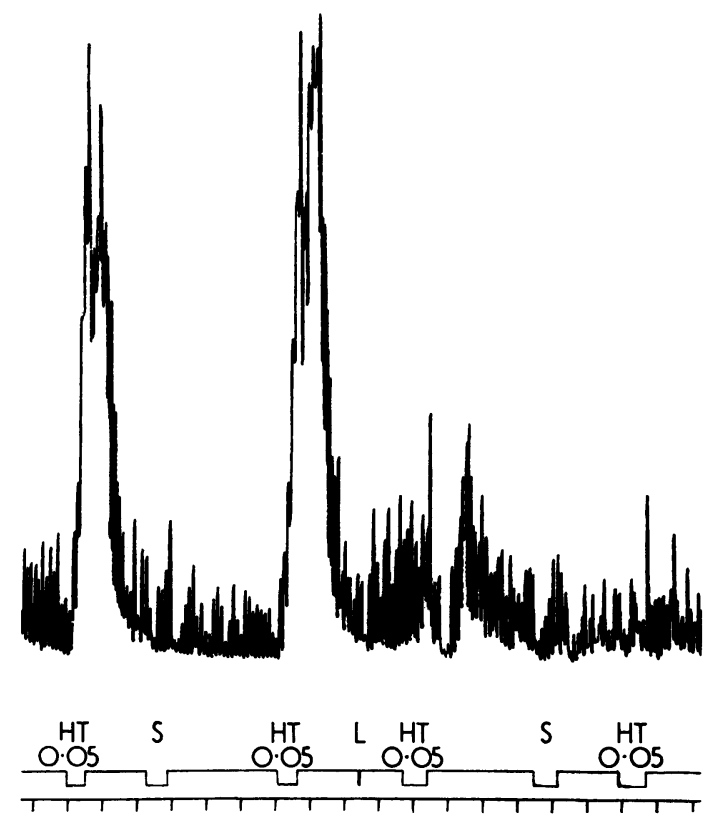

FIG. 4. Jejunum: circular muscle: antagonism of 5-HT by lysergic acid diethylamide. $H T=5$-hydroxytryptamine. $S=$ normal saline $0.05 \mathrm{ml} . / \mathrm{ml}$. of bath. $L=L . S . D$. $0.5 \mu \mathrm{g}$. Concentration of drugs expressed as $\mu \mathrm{g} . / \mathrm{ml}$. Strip length $25 \mathrm{~mm}$. Tension $2.5 \mathrm{~g}$. Lever magnification $\times 7$. Time interval 60 seconds.
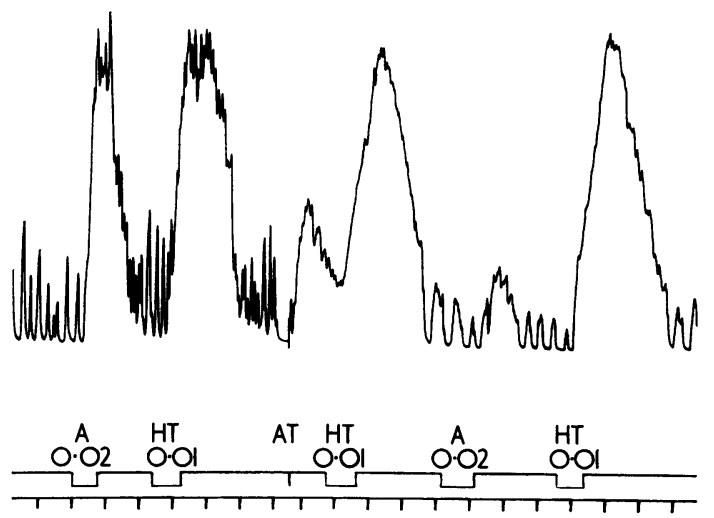

FIG. 5. Jejunum: longitudinal muscle. 5-HT is not antagonised by atropine. $A=$ acetylcholine. $H T=5-$ hydroxytryptamine. $A T=$ atropine $50 \mu g$. (exposed for 5 minutes then washed out). Concentration of drugs expressed as $\mu \mathrm{g} . / \mathrm{ml}$. Strip length $25 \mathrm{~mm}$. Tension $2 \mathrm{~g}$. Lever magnification $\times 7$. Time interval 60 seconds. 
by atropine (Fig. 5) or procaine. The concentration of these antagonists was the same as used previously.

\section{DISCUSSION}

These experiments show that the response to 5-HT of the muscle from various parts of the upper alimentary tract differs from region to region. The longitudinal muscle from the body of the stomach responds to 5-HT, frequently a prolonged contraction occurring which is maintaind long after a washout. The circular muscle, on the other hand, appears to be insensitive to the amine. Neither muscle layer of the antrum nor the first part of the duodenum responds to 5-HT but the jejunum is very sensitive. Where 5-HT causes contraction it is not antagonized by atropine or procaine. It is, however, completely abolished by L.S.D. This suggests that 5-HT has a direct action on the muscle and that the stimulus is not mediated via the nervous elements of the bowel wall. The presence of mucosa and submucosa appears to make no difference to the sensitivity of the muscle strips or to the type of response obtained.

Three muscle layers of the stomach are usually described, viz., longitudinal, oblique, and circular. This investigation has been carried out on longitudinal and circular strips which contain all three layers. It is not always easy to cut strips exactly parallel to the fibres of the layer to be investigated and this difficulty possibly accounts for the longitudinal strips from the body of the stomach that responded only slightly to 5-HT. A further investigation of individually dissected layers is called for to determine the activity of the oblique layer. Most of the strips have been taken from the mid-body region and the mid-antral region, so that the exact site of change in response of the longitudinal muscle to 5-HT has not yet been determined. More work is required to clarify this situation.

All the patients from whom strips were taken were subjected to the usual pre-operative medication and anaesthesia. It may be that atropine has some effect on the preparation, but we do not think that this is significant for reasons previously discussed (Fishlock and Parks, 1963b).

There is a danger in directly interpolating results from work in vitro to the normal physiological situation. Nevertheless, these observations are likely to bear a significant relationship to the normal response of these regions to 5-HT. Certainly a similar investigation on the human ileum and colon has had some evidence in vivo to support it. We have previously reported that 5-HT causes the circular muscle of the human ileum to contract but causes the colon to relax. Fink and Friedman (1960), while investigating the motility of the human bowel, concluded that 5-HT administered intravenously inhibits the activity of the left side of the colon. Shepherd (1963) also reported that intra-arterial injection of 5-HT into isolated loops of human bowel resulted in marked spasm of the ileum but no effect on the colon was observed.

Bülbring and Lin (1958) described the relationship of 5-HT to the peristaltic reflex using guinea-pig ileum and rabbit jejunum. Lee (1960), investigating rabbit and guinea-pig preparations, concluded that 5-HT had a similar effect on peristalsis in the colon. The hypothesis that 5-HT functions as a local hormone in the intestine and may be essential for the initiation of the peristaltic reflex was tested by Boullin (1964), who found that the peristaltic responses of 5-HT depleted rats were similar to those of normal or of pair-fed control animals, and he concluded that 5-HT was not essential for peristalsis in the rat.

Although there is much evidence showing that 5-HT affects the motility of the human small bowel (Hendrix et al., 1957; Haverback and Davidson, 1958; Daniel et al., 1960) its precise physiological role is still unknown. It is possible that its effect on motility is incidental. When the functional significance of 5-HT is at last discovered it may be possible to explain why different regions of the human alimentary tract vary in their response to this amine.

\section{SUMMARY}

Longitudinal and circular strips of muscle were taken at operation from the human stomach, duodenum, and jejunum, and were immersed in modified Krebs's solution in an isolated organ bath at $37^{\circ} \mathrm{C}$.

The responses to acetylcholine and 5-HT were recorded. The longitudinal muscle of the body of the stomach regularly contracted in the presence of 5-HT. The circular muscle of the body of the stomach and both muscle layers of the antrum and the first part of the duodenum failed to respond to 5-HT, although they were sensitive to acetylcholine. Both muscle layers of the proximal part of the jejunum were very sensitive to 5-HT and contracted.

Atropine blocked the responses to acetylcholine but not to 5-HT. Lysergic acid diethylamide antagonized the action of 5-HT, but not that of acetylcholine. Procaine did not affect the action of either acetylcholine or 5-HT.

It is concluded that where 5-HT caused contraction it did so by a direct action on the muscle.

This work has been made possible by a grant from the Medical Research Council. 


\section{REFERENCES}

Boullin, D. J. (1964). Observations on the significance of 5-hydroxytryptamine in relation to the peristaltic reflex of the rat. Brit. $J$. Pharmacol., 23, 14-33.

Bülbring, E., Crema, A., and Saxby, O. B. (1958). A method for recording peristalsis in isolated intestine. Ibid., 13, 440-443.

- and Lin, R. C. Y. (1958). The effect of intraluminal application of 5-hydroxytryptamine and 5-hydroxytryptophan on peristalsis; the local production of 5-HT and its release in relation to intraluminal pressure and propulsive activity. J. Physiol. (Lond.), 140, 381-407.

Daniel, E. E., Honour, A. J., and Bogoch, A. (1960). Antagonism of serotonin-induced contraction and electrical activity in the ileum. Gastroenterology, 39, 62-73.

Erspamer, V. (1940). Pharmakologische Studien über Enteramin. I. Uber die Wirkung von Acetonextrakten der Kaninchenmagenschleimhaut auf den Blutdruck und auf isolierte überlebende Organe. Naunyn-Schmiedeberg's Arch. exp. Path. Pharmak., 196, 343-365.

- (1952). Enteramina e 5-metossitriptamina: tossicità; azione sulla diuresi, sulla pressione del sangue e su alcuni organi a muscolatura liscia. Ric. sci., 22, 694-702.

Fink, S., and Friedman, G. (1960). The differential effect of drugs on the proximal and distal colon. Amer. J. Med., 28, 534-540.
Fishlock, D. J. (1964). The action of 5-hydroxytryptamine on the circular muscle of the human ileum and colon in vitro. J. Physiol. (Lond.), 170, 11-12P.

- and Parks, A. G. (1963a). A study of human colonic muscle in vitro. Brit. med. J., 2, 666-667.

- and Parks, A. G. (1963b). Nicotine and colonic muscle. Ibid., 2, 1528.

Gaddum, J. H. (1953). Tryptamine receptors. J. Physiol. (Lond.), 119, 363-368.

- and Hameed, K. A. (1954). Drugs which antagonize 5-hydroxytryptamine. Brit. J. Pharmacol., 9, 240-248.

Haverback, B. J., and Davidson, J. D. (1958). Serotonin and the gastrointestinal tract. Gastroenterology, 35, 570-578.

Hendrix, T. R., Atkinson, M., Clifton, J. A., and Ingelfinger, F. J. (1957). The effect of 5-hydroxytryptamine on intestinal motor function in man. Amer. J. Med., 23, 886-893.

Lee, C. Y. (1960). The effect of stimulation of extrinsic nerves on peristalsis and on the release of 5-hydroxytryptamine in the large intestine of the guinea-pig and of the rabbit. J. Physiol. (Lond.), 152, 405-418.

Shepherd, J. J. (1963). Serotonin and gut motility. Brit. med. J., 2, 1589.

Vane, J. R. (1957). A sensitive method for the assay of 5-hydroxytryptamine. Brit. J. Pharmacol., 12, 344-349. 